\section{Light, dark, and melatonin: emerging evidence for the importance of melatonin in ocular physiology}

\begin{abstract}
Melatonin is a hormone, which is mainly produced by the pineal gland, a vestigial eye. Rather than the rods and cones, it is a newly discovered subgroup of photosensitive retinal ganglion cells, which is responsible for mediating the light-dark cycles, thus regulating melatonin's secretion. One of the correlates of the circadian rhythm of melatonin release is the habitual sleep pattern. Patients with circadian rhythm sleep disorders, including some blind patients with no light-induced suppression of melatonin, benefit from melatonin treatment. Melatonin is synthesized in the retina, lens, ciliary body as well as other parts of the body. In this review, we discuss the physiological roles of melatonin in the eye, as well as the potential therapeutic avenues currently under study. Eye (2007) 21, 901-908; doi:10.1038/sj.eye.6702597; published online 22 September 2006
\end{abstract}

Keywords: melatonin; circadian rhythms; retinal ganglion cells; sleep

\section{Introduction}

Deep beneath the cerebral cortices, a vestigial eye measures and keeps time. In a sense, the pineal gland is ophthalmology territory. Few clinical situations draw the pineal gland to the ophthalmologist's attention: calcified in later life and thus radio-opaque, it was historically an important radiological marker of midline shift on plain X-ray. Pineal enlargement by tumour may obstruct the cerebral aqueduct causing papilloedema or damage the nearby tectal structures causing Parinaud's syndrome. Only very rarely are we reminded of its phylogenetic origin as the third eye, when a mutation in its modified photoreceptors results in 'trilateral retinoblastoma'. Its product, the hormone melatonin has been the subject of intense research and turns out to be a simple molecule of fundamental importance to many quite disparate physiological systems in the human body, including the eye. This review of melatonin describes: the nonvisual ocular photoreceptive pathway that regulates melatonin production, melatonin's influence on circadian rhythms, in particular its effect on sleep cycles, the current knowledge of melatonin's actions within the eye, and finally its side effect profile.

\section{Melatonin}

Melatonin, first identified in the late 1950s was given its name to reflect its melanin granuleaggregating effect. ${ }^{1}$ This very ancient molecule exists in organisms as simple and primitive as prokaryotes and as complex as humans. ${ }^{2}$ It acts as a free radical scavenger and an antioxidant, possibly its initial function 2-3.5 billion years ago. Since then its actions have diversified in increasingly complex organisms and range from circadian adjustments, ${ }^{3}$ to a function in seasonal reproduction. ${ }^{4}$ It acts on the suprachiasmatic nucleus to modify the timing of sleep, causing relative hypothermia, ${ }^{5}$ and in the retina, rod disc shedding. ${ }^{6}$

Although melatonin is present in food such as fruit, vegetables, and wheat, ${ }^{7}$ melatonin ingested with a normal diet does not significantly contribute to circulating levels. Instead, it is mostly produced by the pineal gland, and the retina, ${ }^{8}$ lens, ${ }^{9}$ iris, ciliary body, ${ }^{10}$
${ }^{1}$ Department of Ophthalmology, British Columbia Children's Hospital, Vancouver, British Columbia, Canada

${ }^{2}$ Principal investigator, Melatonin Research Group, Mental Health Research Unit, British Columbia Children's Hospital, Vancouver, British

Columbia, Canada

Correspondence: CJ Lyons,

Department of Ophthalmology, Room A 136, British Columbia Children's Hospital, 4480 Oak Street, Vancouver, British Columbia,

Canada V6H 3V4

Tel: + 0016048752345 ; Fax: +001604 8753561 E-mail: clyons@cw.bc.ca

Received: 23 March 2006 Accepted in revised form: 8 August 2006 Published online: 22 September 2006

A presentation based on this review was made at the meeting 'Pediatric Ophthalmology, Adult Strabismus', Vancouver, September 2005 
lacrimal gland, ${ }^{11}$ skin, $^{12}$ and gut ${ }^{13}$ also produce small amounts. It is synthesized through conversion of tryptophan to serotonin, then to $N$-acetylserotonin, and finally to melatonin (or N-acetyl-5methoxytryptamine). ${ }^{14}$ Two enzymes, arylalkylamine $\mathrm{N}$-acetyltransferase (NAT) and hydoxyindole-Omethyltransferase catalyse the rate-limiting steps.

Serum melatonin concentration varies with age: normal neonates secrete very little but levels rise shortly thereafter and become circadian at about 2-3 months of age, ${ }^{15}$ coinciding with a more rhythmical sleep-wake pattern. Daytime concentrations remain low throughout life but night time concentrations peak in humans between 1 and 3 years of age, ${ }^{16}$ gradually reducing through puberty owing to dilution in the increased body volume. ${ }^{17}$ The diurnal variation persists in adulthood with peak serum levels occurring between 2 AM and 4 AM. Eventually, in old age, this prominent night-time peak becomes markedly attenuated. ${ }^{18}$

\section{Light control of pineal melatonin secretion}

It has been suspected for some time that different photoreceptors subserve sight and melatonin production. Thus, some blind people without pupil light reflexes have light-induced suppression of melatonin secretion; their eyes serve more than a cosmetic function as they do not report insomnia. ${ }^{19}$ Conversely, blind patients without light-induced suppression of melatonin do have sleep disorders.

A 'non-rod', 'non-cone' photoreceptor was suspected when transgenic mice lacking both rods and cones were nevertheless found to have light-responsive clocks. ${ }^{20}$ Furthermore, monochromatic blue light of 446-477 nm wavelength was found to be the strongest input for melatonin regulation in healthy subjects, suggesting that a photo pigment distinct from that of rods and cones was responsible for melatonin regulation. ${ }^{21}$

The mystery photoreceptor involved in melatonin regulation was identified a couple of years ago: it is the retinal ganglion cell. ${ }^{22}$ A total of $0.2 \%$ of retinal ganglion cells contain melanopsin and respond directly to light even when isolated pharmacologically or physically from other retinal neurons. ${ }^{23}$ In addition to being intrinsically photosensitive, they are activated by rods and cones and have an unusual colour-opponent receptive field where an $\mathrm{S}$ cone-mediated Off response is antagonistic to an $(\mathrm{L}+\mathrm{M})$ cone-mediated On response. ${ }^{23}$ The dendritic networks of these photosensitive retinal ganglion cells cover large areas of retina with peak densities in the parafoveal retina. ${ }^{23}$ They react slowly but tonically to luminance changes ${ }^{24}$ and stimulation of the nasal hemiretina causes maximal melatonin suppression in humans. ${ }^{25}$ In the mouse, rod and cone photoreceptors only become light responsive at the 10th postnatal day, whereas intrinsically photosensitive retinal ganglion cells expressing melanopsin are light sensitive from birth. ${ }^{26}$ These photosensitive retinal ganglion cells are directly connected to (1) the suprachiasmatic nucleus for circadian photoentrainment, (2) the lateral geniculate body possibly contributing to conscious visual perception, $^{23}$ and (3) the olivary pretectal nucleus to drive the pupillary light reflex.

It is thought that at least one other photopigment must be involved in light-dark circadian rhythm entrainment because mice without melanopsin have an attenuated but recordable bright light phase shift in circadian rhythms. Also vitamin A depletion (detrimental to melanopsin, rods, and cone functioning) does not degrade pupillary light responses and circadian entrainment to light-dark cycle, and not all ganglion cells that project to the suprachiasmatic nucleus contain melanopsin.

Currently, cryptochromes that function in blue light are considered likely candidates. ${ }^{27}$ Cryptochromes undergo a conformational change on exposure to light ${ }^{28}$ and are involved in light responsive induction of c-fos (a marker for circadian phototransduction) in the suprachiasmatic nucleus. ${ }^{27}$

Photic input to the suprachiasmatic nucleus is not the sole modulator of circadian rhythms and melatonin secretion. The suprachiasmatic nucleus contains heterogeneous cells and is part of a large neurological network receiving and sending synaptic and neurochemical messages. Craniopharyngiomas can cause damage to the suprachiasmatic nucleus. Affected patients in addition to having neuroendocrinopathies, can have alterations of their sleep-wake cycles and cognitive abilities. ${ }^{29}$

The genetic basis of time keeping has recently been elucidated: it is based on a feedback loop system in which a gene produces a protein which inhibits the activation of that gene. The mouse circadian clock depends on a complex set of interacting positive and negative genetic transcriptional feedback loops involving transcriptional factors named Clock and BMAL1/ Mop3, ${ }^{30}$ three period genes and two cryptochrome genes. ${ }^{31}$ It is likely that numerous other as yet unidentified genes are involved in rhythm generation. Although some other mammalian tissues have been demonstrated to independently generate circadian rhythms, it appears that the suprachiasmatic nucleus is the principal regulator of circadian behaviours. ${ }^{30}$

\section{Neuroanatomy}

In mammals, the components of circadian melatonin rhythm production are distributed in three different areas, all in the diencephalon: the photoreceptors are 
in the retina, the endogenous oscillator (the 'internal clock' which sets the cycle length) in the suprachiasmatic nucleus of the hypothalamus, and the neuroendocrine effector in the pineal gland which produces melatonin in a rhythmic pattern.

Fibres from the suprachiasmatic nucleus of the hypothalamus follow the sympathetic pathway to supply the pineal gland. With the onset of darkness, these sympathetic fibres release noradrenalin to initiate the intracellular release of stored serotonin and NAT. ${ }^{32}$ Patients with preganglionic sympathectomy owing to cervical cord lesions ${ }^{33}$ and diabetics with clinical autonomic neuropathy ${ }^{34}$ lack a normal diurnal melatonin rhythm. Melatonin has high lipid ${ }^{35}$ and aqueous ${ }^{36}$ solubility allowing it to cross the blood-brain barrier into the circulation and into cell organelles.

\section{Circadian rhythms}

Animals adapt to rhythmic environmental changes such as the light/dark, tidal, and seasonal cycles. Circadian rhythms, whose period is about $24 \mathrm{~h}$, are virtually ubiquitous, occurring in cyanobacteria, fungi, algae, plants, and animals. ${ }^{37}$ The circadian rhythm of melatonin release is responsible for modifying habitual sleep patterns. The day-night cycle modifies this rhythm. Subjects kept in total darkness or constant illumination (and some blind people) revert to an intrinsic cycle of melatonin secretion of between 24.2 and $24.9 \mathrm{~h}$. As they lose up to an hour a day, they are completely out of synchrony after $2-3$ weeks. ${ }^{38}$ There are two case reports of children whose pineal glands were destroyed by tumours, resulting in absent pineal melatonin production. They both had severe sleep difficulties, which were corrected by melatonin supplementation. ${ }^{39,40}$

Light has two effects on melatonin: day-night light cycles modify the rhythm of its secretion and brief pulses of light of sufficient intensity and duration abruptly suppress its production. ${ }^{41}$ The circadian rhythm of pineal melatonin secretion reflects signals originating in the suprachiasmatic nucleus. ${ }^{42}$ Lubkin et al ${ }^{43}$ wrote an excellent review on the importance of signals sent via the retinohypothalmic tract in synchronizing circadian rhythms of cortisol, growth hormone, and gonadotropins. However, the rhythm of melatonin synthesis in the retina and ciliary body is synchronized with, but independent from, the rhythm of melatonin synthesis in the pineal gland. ${ }^{8,10}$ In birds, maintained in constant light with each eye alternately patched for $12 \mathrm{~h}$, ocular melatonin rhythms were found to have opposite phases suggesting independent ocular circadian oscillators. ${ }^{44}$ Also pinealectomy does not attenuate melatonin levels in the gut or its circadian rhythm; ${ }^{45}$ in rats the gut's melatonin levels may by determined by when the mammal eats. ${ }^{46}$

\section{Melatonin, sleep disorders, and visual impairment}

Patients who are blind from ocular causes and who have abnormal sleep-wake cycles may benefit from exogenous melatonin, as may patients with cortical visual impairment and neurodevelopmental delay. ${ }^{47}$ The latter have a markedly diminished appreciation of all the zeitgebers (contextual clues that it is sleep time), including light and darkness, and hence have difficulties in synchronizing their sleep-wake cycles with the environment.

Sleep plays a major role in brain maturation and chronic sleep disorders can adversely affect a child's development. ${ }^{48,49}$ Furthermore, the sleep-wake disturbances of visually impaired infants can place significant stress on the parents and siblings. Exogenous melatonin has proved useful in visually impaired children with sleep-wake rhythm disorders. ${ }^{50}$ It is most effective when given at the desired bedtime, as it may have deleterious effects on sleep if given at other times. ${ }^{14}$ An accurate diagnosis is critical in the melatonin treatment of sleep disorders because it is most effective for circadian rhythm sleep disorders owing to the hormone's chronobiotic properties.

Melatonin treatment starts with a low dose, for example, $1-3 \mathrm{mg}$ in toddlers and 2-4 mg in older children given at the desired bedtime. The dose is gradually increased, every few days, until there is a satisfactory response (eg 6-10 mg). Adults appear to need smaller doses than children (1-4 mg). Children with severe brain damage and chronic sleep difficulties may require higher doses, even up to $15 \mathrm{mg}$. Physicians should use the clinical response to determine the appropriate dose.

Melatonin is eliminated from the body within 3-4h, although controlled release formulations lasts longer. Therefore, the type of sleep disorder should influence the type of formulation chosen. When the treatment is successful it should be temporarily discontinued after 6-12 months, to see whether it is still necessary. Some individuals with severe neuropsychiatric developmental disorders may require melatonin supplementation for their lifetime.

Melatonin has also proved useful in alleviating jet lag. A Cochrane review concluded that $2-5 \mathrm{mg}$ melatonin taken at bedtime after arrival is effective and may be worth repeating for the next $2-4$ days. ${ }^{51}$

\section{The eye and melatonin}

Like all other tissues, the eye is subject to the effect of melatonin. In addition, a number of structures within the eye synthesize it. 


\section{The retina}

The retina has a light-mediated feedback system; melatonin mediates darkness-related adaptive changes, and dopamine mediates light-related changes. Melatonin is synthesized in the retina by a subpopulation of photoreceptors in a diurnal rhythm. ${ }^{52}$ There are melatonin receptors in the RPE cells ${ }^{53}$ and in the outer plexiform layer of the retina. ${ }^{54}$ Histologically melatonin causes aggregation of melanin in the RPE and clumping of pigment granules in the chromatophores in the choroid. ${ }^{55}$ It activates disc shedding in rod photoreceptors, ${ }^{6}$ and elongation of cone photoreceptors. ${ }^{56}$ Melatonin blocks apoptosis after experimentally induced RPE cell ischaemia. ${ }^{57}$ It also decreases electroretinogram responses as demonstrated in a double blind placebo crossover study in which melatonin given in the afternoon suppressed the b wave amplitude under both photopic and scotopic conditions. ${ }^{58}$

Dopamine has the opposite effect to melatonin and can mimic light in entraining and phase shifting the circadian oscillator which controls melatonin rhythmicity. ${ }^{59}$

Melatonin inhibits release of retinal dopamine via a specific, receptor-mediated mechanism ${ }^{60}$ and stimulation of dopamine receptors markedly suppresses the nocturnal increase of NAT enzyme activity in the retina. ${ }^{61}$

\section{Melatonin and intraocular pressure}

Intraocular pressure (IOP) has a diurnal variation, the trough occurring when melatonin concentration levels are highest, so it is not surprising that melatonin has been studied as a possible antiglaucoma agent. Melatonin receptors have been found in the iris-ciliary processes in rabbits ${ }^{62}$ and localized to the nonpigmented ciliary epithelium in the frog. ${ }^{54} \mathrm{NAT}$, the rate-limiting enzyme involved in the synthesis of melatonin from serotonin has been shown to have higher activity in the iris root-ciliary body complex at night than in the morning. ${ }^{63}$

Studies regarding the effect of melatonin on IOP have had conflicting results. Topical melatonin administration in rabbits causes dose-dependent IOP lowering which is maximal an hour after administration, the effect wearing off over the next $3 \mathrm{~h}$. There are three known melatonin receptors: MT1, MT2, and MT3. A topically applied selective MT3 receptor agonist lowers the IOP significantly more than melatonin, the effect lasting over $6 \mathrm{~h}$ suggesting that melatonin is a partial MT3 receptor agonist. ${ }^{64}$ Conversely, another study group using the same breed of rabbits found a rise in IOP when melatonin was given by injection into a superior vortex vein. ${ }^{65} \mathrm{~A}$ third study involving intracameral infusion of melatonin in cats reduced aqueous production, but

caused a greater reduction in outflow, resulting in a net IOP rise. ${ }^{10} \mathrm{~A}$ topical MT3 receptor agonist reduced IOP in monkeys with laser-induced glaucoma. The hypotensive effect was enhanced with repeated doses, reducing IOP by $7.0 \pm 1.1 \mathrm{mmHg}$ (mean \pm SEM) after 5 days of twice daily dosing. ${ }^{66}$

Samples $e t \mathrm{al}^{67}$ did a series of experiments on humans: in a randomized crossover study exposing subjects to either dim or bright light for $23 \mathrm{~h}$, they found that those exposed to bright light had reduced urinary 6-OH melatonin levels and an attenuated early morning fall in IOP. In a second randomized experiment, they administered oral melatonin to subjects kept in bright light for $23 \mathrm{~h}$ and found it caused a small but significant decrease in IOP. In their third randomized experiment, they administered one dose of melatonin or placebo at 1800 hours and measured the IOP hourly up to midnight. Those given melatonin had a statistically significant (but not a clinically significant) reduction in IOP. ${ }^{67}$

\section{Melatonin and the lens}

Melatonin is produced within the lens in a circadian rhythm, ${ }^{9}$ where it acts as an antioxidant; melatonin administered to rats immediately following ultraviolet-B light was found to reduce cataract formation. ${ }^{68}$ In glutathione-depleted rats (ie rats under oxidative stress), melatonin also significantly reduced the incidence of cataracts and, in addition, stimulated glutathione production. $^{69}$

Melatonin has been shown to be an important antioxidant both at physiological and pharmacological concentrations. ${ }^{70}$ It is more effective than mannitol and vitamin $\mathrm{E}_{,}^{71}$ and is about five times more efficient a scavenger of the hydroxyl radical than glutathione. ${ }^{72}$ Experimentally, melatonin has been shown to cause some restoration in vitamin $\mathrm{C}$ and $\mathrm{E}$ levels (nonenzymatic antioxidants) and the activity of catalase (an enzymatic antioxidant) in cells exposed to oxidative stress. ${ }^{73}$ In vitro studies show that melatonin scavenges a common oxidant - nitric oxide. ${ }^{74}$ It also protects against chromosomal damage caused by ionizing radiation and other oxidative stresses. ${ }^{73}$ Whereas most antioxidants can only function within certain subcellular compartments, its lipid ${ }^{35}$ and aqueous ${ }^{36}$ solubility allow access to virtually all parts of the cell.

\section{Melatonin and the cornea and sclera}

Melatonin receptors have been demonstrated in the corneal epithelium, stroma, and endothelium as well as the sclera of Xenopus (frog) eyes. ${ }^{75}$ Melatonin's action via these receptors is presently speculative. Normal corneal growth and development is dependent on a regular 
diurnal rhythm of light and dark; young chicks exposed to continuous illumination develop severe corneal flattening and thickening. ${ }^{76}$ The growth of the sclera and axial elongation are known to follow a circadian rhythm. ${ }^{77}$ The epithelial cells of the corneal also have a circadian rhythm, with a high mitotic rate at night and low rate during the day. Injection of melatonin induces a phase advance of the corneal mitotic rhythm in normal light/dark conditions. ${ }^{78}$ The exact effect of exogenous melatonin on these important ocular characteristics and possible therapeutic avenues for the treatment of conditions as disparate as corneal epithelial defects and pathological myopia, remains to be determined.

\section{Systemic effects: light exposure and breast cancer}

Several papers have shown that women blind to light have a reduced risk of developing breast cancer. People living in low levels of ambient lighting such as the Arctic also have a lower prevalence of breast cancer. Conversely, women exposed to light at night (eg night and shift workers) have a higher incidence of breast cancer. A simultaneous decline in serum melatonin levels with increasing tumour growth has been demonstrated in preoperative breast cancer patients. ${ }^{79}$ Decreased melatonin secretion has also been noted in patients with other type of cancers. ${ }^{80}$ Both physiological and pharmacological levels of administered melatonin demonstrate oncostatic properties. ${ }^{81}$ Future research may allow us to evaluate what is and what is not a safe level of exposure to night lights.

\section{Pharmacokinetics}

Orally administered melatonin is rapidly absorbed - half-life absorption of $24 \mathrm{~min}$. Its bioavailability varies widely - normal subjects given $80 \mathrm{mg}$ of melatonin had serum melatonin concentrations between 350 and 10000 times higher than the usual night time peak $60-150 \mathrm{~min}$ later. ${ }^{82}$ Absorbed melatonin is rapidly metabolized, chiefly in the liver $^{83}$ it is excreted in the urine. The chief urinary metabolite of melatonin closely parallels serum melatonin concentrations. ${ }^{82}$ Regular melatonin is eliminated from the body within 3-4 $\mathrm{h}$, whereas sustained-release preparations produce therapeutic levels for 6-8h.

\section{Side effects}

In the UK, melatonin is available only on prescription. However, numerous synthetic melatonin preparations are available in health-food stores in the USA and Canada. Anecdotal reports of headache, restlessness, confusion, nausea, tachycardia, and pruritus have been attributed to the use of melatonin. These may have been caused by impurities in some melatonin products. ${ }^{14}$ A mild heaviness in the legs has been reported for a few minutes following melatonin injection. ${ }^{84}$ When given during the day, melatonin causes tiredness. ${ }^{85}$ Some patients report an increase in dreaming or the occurrence of more vivid dreams, this is particularly noted in the elderly. ${ }^{86}$ One report suggested that it was a proconvulsant, ${ }^{87}$ but other studies have demonstrated that it has a clinically significant anticonvulsant action. ${ }^{88,89}$ It may have an adverse immunomodulatory effect on asthma, ${ }^{90}$ although a randomized controlled trial showed that melatonin therapy improves the sleep of patients with asthma without adverse effects. ${ }^{91}$

The relationship between melatonin and sex hormones in humans is still being elucidated. Melatonin has been elegantly demonstrated to be progonadal in short-day breeders such as sheep, and antigonadal in long-day breeders such as the Syrian hamster. ${ }^{92}$ In disorders of the reproductive system in humans, there is abnormal melatonin secretion and abnormalities of the pineal gland can perturb the reproductive system. Extremely high circulating levels of melatonin may delay puberty and cause hypogonadism, as noted in a case report of a boy. ${ }^{93}$ Melatonin has been investigated as a possible contraceptive drug; when $300 \mathrm{mg}$ was given in the evening, ovulation was partially inhibited in normal women. ${ }^{92}$ In men taking $2 \mathrm{mg}$ melatonin a day for 1 month, there was no alteration in levels of testosterone or luteinizing hormone. ${ }^{94}$ Melatonin may lower growth hormone levels. ${ }^{95}$

In animals, a maximal safe dose has not been established; even enormous doses such as $800 \mathrm{mg} / \mathrm{kg}$ are not lethal. ${ }^{96}$ In a study of 11 patients, doses up to a massive $6600 \mathrm{mg} /$ day for 35 days were given with no severe toxicities occurring. ${ }^{97}$

\section{Conclusion}

Across the animal spectrum, there is evidence of circadian time-keeping activity, dating back hundreds of millions of years, attesting to the fundamental importance of synchrony with the environment to the survival of each organism. A key molecule responsible for this, melatonin, was discovered less than 50 years ago and is now produced biosynthetically. Although just as valid as other biosynthetically produced hormones such as growth hormone or oestrogen, its relatively recent discovery means that many of its actions remain obscure. The ambiguity of its status as a drug has limited public availability to health food outlets in the USA, where this important substance is at risk of becoming labeled as an 'alternative medicine' in the public mind. 
Although associated with the pineal gland and produced primarily in relation with the day-night cycle, melatonin turns out to have a huge spectrum of potential applications. Outside ophthalmology, melatonin is being evaluated in areas as diverse as cancer, haematology, toxicology, sleep, cardiology, ageing, immunity, and osteoporosis. Its fundamental role in morphological signaling during embryogenesis might suggest a possible application of this hormone in extreme prematurity where infants, in the absence of maternal melatonin, have consecutively no, little, and disturbed melatonin production over the course of their development. In this context, melatonin's role in the pathogenesis of retinopathy of prematurity and myopia of prematurity should be assessed. In the adult, melatonin could have a role in cataract prevention, IOP reduction, and neuroprotection.

The areas outlined above are a glimpse of the exciting possibilities that exist. Only through continuing careful scientific evaluation will this fundamental molecule find its true place within the practice of modern medicine.

\section{Acknowledgements}

The authors have no commercial or proprietary interest in any product or concept discussed in this article.

\section{References}

1 Lerner AB, Case JD, Takahashi Y, Lee TH, Wataru M. Isolation of melatonin, the pineal gland factor that lightens melanocytes. J Am Chem Soc 1958; 80: 2587.

2 Manchester LC, Poeggeler B, Alvares FL, Ogden GB, Reiter RJ. Melatonin immunoreactivity in the photosynthetic prokaryote Rhodospirillum rubrum: implications for an ancient antioxidant system. Cell Mol Biol Res 1995; 41: 391-395.

3 Liu C, Weaver DR, Jin X, Shearman LP, Pieschl RL, Gribkoff VK et al. Molecular dissection of two distinct actions of melatonin on the suprachiasmatic circadian clock. Neuron 1997; 19: 91-102.

4 Bartness TJ, Powers JB, Hastings MH, Bittman EL, Goldman $\mathrm{BD}$. The timed infusion paradigm for melatonin delivery: what has it taught us about the melatonin signal, its reception, and the photoperiodic control of seasonal responses? J Pineal Res 1993; 15: 161-190.

5 Hughes RJ, Badia P. Sleep-promoting and hypothermic effects of daytime melatonin administration in humans. Sleep 1997; 20: 124-131.

6 Besharse JC, Dunis DA. Methoxyindoles and photoreceptor metabolism: activation of rod shedding. Science 1983; 219: 1341-1343.

7 Hattori A, Migitaka H, Iigo M, Itoh M, Yamamoto K, Ohtani-Kaneko $\mathrm{R}$ et al. Identification of melatonin in plants and its effects on plasma melatonin levels and binding to melatonin receptors in vertebrates. Biochem $\mathrm{Mol}$ Biol Int 1995; 35: 627-634.
8 Yu HS, Pang SF, Tang PL. Increase in the level of retinal melatonin and persistence of its diurnal rhythm in rats after pinealectomy. J Endocrinol 1981; 91: 477-481.

9 Tan DX, Manchester LC, Hardeland R, Lopez-Burillo S, Mayo JC, Sainz RM et al. Melatonin: a hormone, a tissue factor, an autocoid, a paracoid, and an antioxidant vitamin. I Pineal Res 2003; 34: 75-78.

10 Rohde BH, McLaughlin MA, Chiou LY. Existence and role of endogenous ocular melatonin. J Ocul Pharmacol 1985; 1: 235-243.

11 Mhatre MC, van Jaarsveld AS, Reiter RJ. Melatonin in the lacrimal gland: first demonstration and experimental manipulation. Biochem Biophys Res Commun 1988; 153: $1186-1192$.

12 Slominski A, Pisarchik A, Semak I, Sweatman T, Wortsman J, Szczesniewski A et al. Serotoninergic and melatoninergic systems are fully expressed in human skin. FASEB J 2002; 16: 896-898.

13 Bubenik GA. Localization, physiological significance and possible clinical implication of gastrointestinal melatonin. Biol Signals Recept 2001; 10: 350-366.

14 Jan JE, Freeman RD, Fast DK. Melatonin treatment of sleepwake cycle disorders in children and adolescents. Dev Med Child Neurol 1999; 41: 491-500.

15 Ardura J, Gutierrez R, Andres J, Agapito T. Emergence and evolution of the circadian rhythm of melatonin in children. Horm Res 2003; 59: 66-72.

16 Waldhauser F, Ehrhart B, Forster E. Clinical aspects of the melatonin action: impact of development, aging, and puberty, involvement of melatonin in psychiatric disease and importance of neuroimmunoendocrine interactions. Experientia 1993; 49: 671-681.

17 Griefahn B, Brode P, Blaszkewicz M, Remer T. Melatonin production during childhood and adolescence: a longitudinal study on the excretion of urinary 6hydroxymelatonin sulfate. J Pineal Res 2003; 34: 26-31.

18 Iguichi H, Kato KI, Ibayashi H. Age-dependent reduction in serum melatonin concentrations in healthy human subjects. J Clin Endocrinol Metab 1982; 55: 27-29.

19 Czeisler CA, Shanahan TL, Klerman EB, Martens H, Brotman DJ, Emens JS et al. Suppression of melatonin secretion in some blind patients by exposure to bright light. N Engl J Med 1995; 332: 6-11.

20 Lucas RJ, Freedman MS, Munoz M, Garcia-Fernandez JM, Foster RG. Regulation of the mammalian pineal by non-rod, non-cone, ocular photoreceptors. Science 1999; 284: 505-507.

21 Brainard GC, Hanifin JP, Greeson JM, Byrne B, Glickman G, Gerner $\mathrm{E}$ et al. Action spectrum for melatonin regulation in humans: evidence for a novel circadian photoreceptor. J Neurosci 2001; 21: 6405-6412.

22 Hattar S, Liao HW, Takao M, Berson DM, Yau KW. Melanopsin-containing retinal ganglion cells: architecture, projections, and intrinsic photosensitivity. Science 2002; 295: 1065-1070.

23 Dacey DM, Liao HW, Peterson BB, Robinson FR, Smith VC, Pokorny J et al. Melanopsin-expressing ganglion cells in primate retina signal colour and irradiance and project to the LGN. Nature 2005; 433: 749-754.

24 Berson DM, Dunn FA, Takao M. Phototransduction by retinal ganglion cells that set the circadian clock. Science 2002; 295: 1070-1073.

25 Visser EK, Beersma DG, Daan S. Melatonin suppression by light in humans is maximal when the nasal part of the retina is illuminated. J Biol Rhythms 1999; 14: 116-121. 
26 Sekaran S, Lupi D, Jones SL, Sheely CJ, Hattar S, Yau KW et al. Melanopsin-dependent photoreception provides earliest light detection in the mammalian retina. Curr Biol 2005; 15: 1099-1107.

27 Thompson CL, Selby CP, Partch CL, Plante DT, Thresher RJ, Araujo $\mathrm{F}$ et al. Further evidence for the role of cryptochromes in retinohypothalamic photoreception/ phototransduction. Brain Res Mol Brain Res 2004; 122: 158-166

28 Partch CL, Clarkson MW, Ozgur S, Lee AL, Sancar A. Role of structural plasticity in signal transduction by the cryptochrome blue-light photoreceptor. Biochemistry 2005; 44: 3795-3805.

29 Cohen RA, Albers HE. Disruption of human circadian and cognitive regulation following a discrete hypothalamic lesion: a case study. Neurology 1991; 41: 726-729.

30 Hastings MH, Herzog ED. Clock genes, oscillators, and cellular networks in the suprachiasmatic nuclei. J Biol Rhythms 2004; 19: 400-413.

31 Etchegaray JP, Lee C, Wade PA, Reppert SM. Rhythmic histone acetylation underlies transcription in the mammalian circadian clock. Nature 2003; 421: 177-182.

32 Pangerl B, Pangerl A, Reiter RJ. Circadian variations of adrenergic receptors in the mammalian pineal gland: a review. J Neural Transm Gen Sect 1990; 81: 17-29.

33 Kneisley LW, Moskowitz MA, Lynch HG. Cervical spinal cord lesions disrupt the rhythm in human melatonin excretion. J Neural Transm 1978; 13(Suppl): 311-323.

34 O'Brien IA, Lewin IG, O'Hare JP, Arendt J, Corrall RJ. Abnormal circadian rhythm of melatonin in diabetic autonomic neuropathy. Clin Endocrinol 1986; 24: 359-364.

35 Costa EJ, Lopes RH, Lamy-Freund MT. Permeability of pure lipid bilayers to melatonin. J Pineal Res 1995; 19: 123-126.

36 Shida CS, Castrucci AM, Lamy-Freund MT. High melatonin solubility in aqueous medium. J Pineal Res 1994; 16: 198-201.

37 Chang DC, Reppert SM. The circadian rhythms of mice and men. Neuron 2001; 29: 555-558.

38 Lewy AJ, Newsome DA. Different types of melatonin circadian secretory rhythms in some blind subjects. J Clin Endocrinol Metab 1983; 56: 1103-1107.

39 Jan JE, Tai J, Hahn G, Rothstein RR. Melatonin replacement therapy in a child with a pineal tumor. J Child Neurol 2001; 16: $139-140$.

40 Etzioni A, Luboshitzky R, Tiosano D, Ben-Harush M, Goldsher D, Lavie P et al. Melatonin replacement corrects sleep disturbances in a child with pineal tumor. Neurology 1996; 46: 261-263.

41 Lewy AJ, Wehr TA, Goodwin FK, Newsome DA, Markey SP. Light suppresses melatonin secretion in humans. Science 1980; 210: 1267-1269.

42 Reppert SM, Weaver DR, Rivkees SA, Stopa EG. Putative melatonin receptors in a human biological clock. Science 1988; 242: 78-81.

43 Lubkin V, Beizai P, Sadun AA. The eye as metronome of the body. Surv Ophthalmol 2002; 47: 17-26.

44 Underwood H, Siopes T, Barrett RK. Does a biological clock reside in the eye of quail? J Biol Rhythms 1988; 3: 323-331.

45 Vakkuri O, Rintamaki H, Leppaluoto J. Plasma and tissue concentrations of melatonin after midnight light exposure and pinealectomy in the pigeon. J Endocrinol 1985; 105: 263-268.

46 Menendez-Pelaez A, Poeggeler B, Reiter RJ, Barlow-Walden L, Pablos MI, Tan DX et al. Nuclear localization of melatonin in different mammalian tissues: immunocytochemical and radioimmunoassay evidence. J Cell Biochem 1993; 53: 373-382.

47 Jan JE, Freeman RD. Melatonin therapy for circadian rhythm sleep disorders in children with multiple disabilities: what have we learned in the last decade? Dev Med Child Neurol 2004; 46: 776-782.

48 Dahl RE, Lewin DS. Pathways to adolescent health sleep regulation and behavior. J Adolesc Health 2002; 31: 175-184.

49 Goergen EM, Bagay LA, Rehm K, Benton JL, Beltz BS. Circadian control of neurogenesis. J Neurobiol 2002; 53 : 90-95.

50 Espezel H, Jan JE, O'Donnell ME, Milner R. The use of melatonin to treat sleep-wake rhythm disorders in children who are visually impaired. J Vis Impair Blind 1996; 90: 34-50.

51 Herxheimer A, Waterhouse J. The prevention and treatment of jet lag. BMJ 2003; 326: 296-297.

52 Tosini G, Doyle S, Menaker M. Melatonin synthesis in the rat retina: cellular localization and circadian regulation. Invest Ophthalmol Vis Sci 1998; 39: S236.

53 Nash MS, Osborne NN. Pertussis toxin-sensitive melatonin receptors negatively coupled to adenylate cyclase associated with cultured human and rat retinal pigment epithelial cells. Invest Ophthalmol Vis Sci 1995; 36: 95-102.

54 Wiechmann AF, Wirsig-Wiechmann CR. Melatonin receptor mRNA and protein expression in Xenopus laevis nonpigmented ciliary epithelial cells. Exp Eye Res 2001; 73: 617-623.

55 Pang SF, Yew DT. Pigment aggregation by melatonin in the retinal pigment epithelium and choroid of guinea-pigs, Cavia porcellus. Experientia 1979; 35: 231-233.

56 Pierce ME, Besharse JC. Melatonin and rhythmic photoreceptor metabolism: melatonin-induced cone elongation is blocked at high light intensity. Brain Res 1987; 405: 400-404.

57 Osborne NN, Nash MS, Wood JP. Melatonin counteracts ischemia-induced apoptosis in human retinal pigment epithelial cells. Invest Ophthalmol Vis Sci 1998; 39: 2374-2383.

58 Emser W, Dechoux R, Weiland M, Wirz-Justice A. Melatonin decreases the amplitude of the b-wave of the human electroretinogram. Experientia 1993; 49: 686-687.

59 Cahill GM, Grace MS, Besharse JC. Rhythmic regulation of retinal melatonin: metabolic pathways, neurochemical mechanisms, and the ocular circadian clock. Cell Mol Neurobiol 1991; 11: 529-560.

60 Dubocovich ML. Pharmacology and function of melatonin receptors. FASEB J 1988; 2: 2765-2773.

61 Zawilska J, Iuvone PM. Catecholamine receptors regulating serotonin $\mathrm{N}$-acetyltransferase activity and melatonin content of chicken retina and pineal gland: D2-dopamine receptors in retina and alpha-2 adrenergic receptors in pineal gland. J Pharmacol Exp Ther 1989; 250: 86-92.

62 Osborne NN. Serotonin and melatonin in the iris/ciliary processes and their involvement in intraocular pressure. Acta Neurobiol Exp 1994; 54(Suppl): 57-64.

63 Chiou GC, Aimoto T, Chiou LY. Melatonergic involvement in diurnal changes of intraocular pressure in rabbit eyes. Ophthalmic Res 1985; 17: 373-378.

64 Pintor J, Martin L, Pelaez T, Hoyle CH, Peral A. Involvement of melatonin MT(3) receptors in the regulation of intraocular pressure in rabbits. Eur J Pharmacol 2001; 416: 251-254.

65 Rohde BH, Li BH, Chiou GC. Effects of melatonin and haloperidol given via vortex vein on the intraocular pressure. Ophthalmic Res 1993; 25: 10-15. 
66 Serle JB, Wang RF, Peterson WM, Plourde R, Yerxa BR. Effect of 5-MCA-NAT, a putative melatonin MT3 receptor agonist, on intraocular pressure in glaucomatous monkey eyes. J Glaucoma 2004; 13: 385-388.

67 Samples JR, Krause G, Lewy AJ. Effect of melatonin on intraocular pressure. Curr Eye Res 1988; 7: 649-653.

68 Bardak Y, Ozerturk Y, Ozguner F, Durmus M, Delibas N. Effect of melatonin against oxidative stress in ultraviolet-B exposed rat lens. Curr Eye Res 2000; 20: 225-230.

69 Abe M, Reiter RJ, Orhii PB, Hara M, Poeggeler B. Inhibitory effect of melatonin on cataract formation in newborn rats: evidence for an antioxidative role for melatonin. J Pineal Res 1994; 17: 94-100.

70 Tan D, Reiter RJ, Chen LD, Poeggeler B, Manchester LC, Barlow-Walden LR et al. Both physiological and pharmacological levels of melatonin reduce DNA adduct formation induced by the carcinogen safrole. Carcinogenesis 1994; 15: 215-218.

71 Reiter RJ. The role of the neurohormone melatonin as a buffer against macromolecular oxidative damage. Neurochem Int 1995; 27: 453-460.

72 Tan DX, Chen LD, Poeggeler B, Manchester LC, Reiter RJ. Melatonin: a potent, endogenous hydroxyl radical scavenger. Endocr J 1993; 1: 57-60.

73 Susa N, Ueno S, Furukawa Y, Ueda J, Sugiyama M. Potent protective effect of melatonin on chromium(VI)-induced DNA single-strand breaks, cytotoxicity, and lipid peroxidation in primary cultures of rat hepatocytes. Toxicol Appl Pharmacol 1997; 144: 377-384.

74 Noda Y, Mori A, Liburdy R, Packer L. Melatonin and its precursors scavenge nitric oxide. J Pineal Res 1999; 27: 159-163.

75 Wiechmann AF, Rada JA. Melatonin receptor expression in the cornea and sclera. Exp Eye Res 2003; 77: 219-225.

76 Li T, Troilo D, Glasser A, Howland HC. Constant light produces severe corneal flattening and hyperopia in chickens. Vision Res 1995; 35: 1203-1209.

77 Papastergiou GI, Schmid GF, Riva CE, Mendel MJ, Stone RA, Laties AM et al. Ocular axial length and choroidal thickness in newly hatched chicks and one-year-old chickens fluctuate in a diurnal pattern that is influenced by visual experience and intraocular pressure changes. Exp Eye Res 1998; 66: 195-205.

78 Sasaki M, Masuda A, Oishi T. Circadian rhythms of corneal mitotic rate, retinal melatonin and immunoreactive visual pigments, and the effects of melatonin on the rhythms in the Japanese quail. J Comp Physiol A 1995; 176: 465-471.

79 Glickman G, Levin R, Brainard GC. Ocular input for human melatonin regulation: relevance to breast cancer. Neuro Endocrinol Lett 2002; 23(Suppl 2): 17-22.

80 Lissoni P, Viviani S, Bajetta E, Buzzoni R, Barreca A, Mauri $\mathrm{R}$ et al. A clinical study of the pineal gland activity in oncologic patients. Cancer 1986; 57: 837-842.

81 Blask DE, Sauer LA, Dauchy RT. Melatonin as a chronobiotic/anticancer agent: cellular, biochemical, and molecular mechanisms of action and their implications for circadian-based cancer therapy. Curr Top Med Chem 2002; 2: 113-132.

82 Waldhauser F, Waldhauser M, Lieberman HR, Deng MH, Lynch HJ, Wurtman RJ et al. Bioavailability of oral melatonin in humans. Neuroendocrinology 1984; 39: 307-313.

83 Lane EA, Moss HB. Pharmacokinetics of melatonin in man: first pass hepatic metabolism. J Clin Endocrinol Metab 1985; 61: 1214-1216.

84 Lissoni P, Barni S, Crispino S, Tancini G, Fraschini F. Endocrine and immune effects of melatonin therapy in metastatic cancer patients. Eur J Cancer Clin Oncol 1989; 25: 789-795.

85 Smits MG, Nagtegaal EE, van der HeJ, Coenen AM, Kerkhof GA. Melatonin for chronic sleep onset insomnia in children: a randomized placebo-controlled trial. J Child Neurol 2001; 16: 86-92.

86 Kayumov L, Zhdanova IV, Shapiro CM. Melatonin, sleep, and circadian rhythm disorders. Semin Clin Neuropsychiatry 2000; 5: 44-55.

87 Sheldon SH. Pro-convulsant effects of oral melatonin in neurologically disabled children. Lancet 1998; 351: 1254.

88 Fauteck J, Schmidt H, Lerchl A, Kurlemann G, Wittkowski W. Melatonin in epilepsy: first results of replacement therapy and first clinical results. Biol Signals Recept 1999; 8: 105-110.

89 Peled N, Shorer Z, Peled E, Pillar G. Melatonin effect on seizures in children with severe neurologic deficit disorders. Epilepsia 2001; 42: 1208-1210.

90 Sutherland ER, Martin RJ, Ellison MC, Kraft M. Immunomodulatory effects of melatonin in asthma. Am J Respir Crit Care Med 2002; 166: 1055-1061.

91 Campos FL, da Silva-Junior FP, de Bruin VM, de Bruin PF. Melatonin improves sleep in asthma: a randomized, double-blind, placebo-controlled study. Am J Respir Crit Care Med 2004; 170: 947-951.

92 Luboshitzky R, Lavie P. Melatonin and sex hormone interrelationships - a review. J Pediatr Endocrinol Metab 1999; 12: 355-362.

93 Puig-Domingo M, Webb SM, Serrano J, Peinado MA, Corcoy R, Ruscalleda J et al. Brief report: melatonin-related hypogonadotropic hypogonadism. N Engl J Med 1992; 327: 1356-1359.

94 Wright J, Aldhous M, Franey C, English J, Arendt J. The effects of exogenous melatonin on endocrine function in man. Clin Endocrinol (Oxford) 1986; 24: 375-382.

95 Nordlund JJ, Lerner AB. The effects of oral melatonin on skin color and on the release of pituitary hormones. J Clin Endocrinol Metab 1977; 45: 768-774.

96 Barchas J, DaCosta F, Spector S. Acute pharmacology of melatonin. Nature 1967; 214: 919-920.

97 Papavasiliou PS, Cotzias GC, Duby SE, Steck AJ, Bell M, Lawrence WH et al. Melatonin and parkinsonism. JAMA 1972; 221: 88-89. 